\title{
The characterisation of clinical isolates of Staphylococcus aureus in Ile-Ife, Nigeria
}

\author{
A. K. AKO-NAI, A. D. OGUNNIYI, A. LAMIKANRA* and S. E. A. TORIMIRO† \\ Departments of Microbiology, "Pharmaceutics (Faculty of Pharmacy), and tPaediatrics and Child Health (Faculty of \\ Health Sciences), Obafemi Awolowo University, Ile-Ife, Oyo State, Nigeria
}

\begin{abstract}
Summary. Of 166 strains of Staphylococcus aureus isolated from hospital patients and staff in Ile-Ife, Nigeria, $32 \%$ were non-typable (NT). The strains were isolated from skin lesions, eye infections, wounds and nasal flora. Isolates from skin lesions or eye and wound infections were more likely to produce protease $(95 \%$ and $78 \%$ respectively) than nasal isolates $(11 \%)$. Nearly all $(99 \%)$ of the strains isolated were resistant to penicillin and $78 \%$ were resistant to tetracycline. Streptomycin resistance occurred in $25 \%$ of isolates; $19 \%$ were resistant to chloramphenicol and $9 \%$ to methicillin.
\end{abstract}

\section{Introduction}

Staphylococcus aureus causes infections at many sites in the body; these include skin, eyes, gastrointestinal tract and vagina. ${ }^{1-4}$ Colonisation is an important step in the chain of events that leads to infection with $S$. aureus. Individuals are likely to become colonised first and become invaded and infected from this source. ${ }^{5,6}$

The characterisation of pathogenic organisms for epidemiological purposes is important in combating outbreaks of infection caused by these organisms. This is of particular interest in developing countries where microbial infections feature very prominently as causes of morbidity and of mortality. It is desirable to characterise $S$. aureus isolates because of the ubiquity of this organism and its proven capacity to cause various types of infections which may occur in epidemic form.

Infections caused by $S$. aureus became prominent in hospitals in the 1950s as a result of the emergence of $S$. aureus strains that were resistant to penicillin alone or to several antimicrobial agents, including streptomycin, tetracycline and chloramphenicol. Some of these strains were also highly invasive and had the capacity to spread; they belonged to the phage-type 80/81 complex, which included types 52A/ $80 / 81$ and $52 / 52 \mathrm{~A} / 80 / 81$. Therefore, it became apparent that phage typing was an important epidemiological tool in the identification of virulent strains of $S$ aureus and it has become a routine technique in developed countries. ${ }^{8}$ However, this is not the case in developing countries where the lack of adequate laboratory facilities for maintenance of phage stocks have made it virtually impossible for this technique to be employed even for research purposes. In the case of Nigeria, for example, only two studies of phage types of $S$. aureus have been reported. ${ }^{9,10}$ Recently, however, we have been involved in a collaborative study with the phage-typing laboratory of the Statens Seruminstitut, Copenhagen, Denmark. The preliminary results of phage typing and in-vitro antibiotic sensitivity testing of clinical isolates of $S$. aureus from hospital patients and staff in Ile-Ife, Nigeria, are reported in this paper.

\section{Materials and methods}

\section{Sample population}

The sample population comprised 550 consecutive in-patients who developed eye, wound or skin infections during their stay at the Obafemi Awolowo University Teaching Hospitals Complex (OAUTHC), Ile-Ife, over a period of 18 months (Jan. 1988-Sept. 1989). Samples were also obtained from the anterior nares of 65 apparently healthy members of the hospital staff.

\section{Collection of samples}

Samples from patients were collected from infected eyes, wounds and septic spots on the skin. Nasal samples were obtained with sterile swabs (Kemi Intressen, Sundyberg, Sweden) moistened with sterile nutrient broth which were inserted into the anterior nare and rotated gently. Infected eyes were swabbed similarly. Purulent material was obtained from open wounds, some of which had become infected after surgery, and from cases of skin sepsis. All the samples were inoculated on to freshly prepared blood agar and Mannitol Salt Agar (MSA; Oxoid) which were incubated at $35^{\circ} \mathrm{C}$ for $48 \mathrm{~h}$. Gram-stained films were examined from those colonies that resembled $S$. aureus 
and fermented mannitol, and these colonies were then tested for coagulase production by the slide agglutination test and confirmed as $S$. aureus by the tube coagulase test.

\section{Determination of extracellular enzyme production}

All the isolates were tested for their ability to produce protease, DNAase and RNAase. Protease activity was assessed by the method of Hankin and Anagnostakis ${ }^{11}$ with gelatin (Oxoid) $4 \%$ in semi-solid medium. The secretion of DNAase and RNAase was detected by a modified version of the method described by Jeffries $e t a l .^{12}$ with DNA $0.2 \%$ or RNA $0.2 \%$ (Sigma) in semi-solid medium as substrates. The inoculum was standardised in nutrient broth according to the method of Bauer $e t$ al. ${ }^{13}$ so that the inoculum contained approximately $10^{8} \mathrm{cfu} / \mathrm{ml}$. A calibrated loopful of $0.001 \mathrm{ml}$ was streaked as a straight line across each plate; the plates were then incubated at $37^{\circ} \mathrm{C}$ for $72 \mathrm{~h}$ and then at $27^{\circ} \mathrm{C}$ for $48 \mathrm{~h}$. Proteolytic activity was read as a clear zone around the line of streak when the gelatin medium was flooded with acid mercuric chloride solution. DNAase and RNAase activities were read similarly after flooding the media with $1 \mathrm{~N} \mathrm{HCl}$.

\section{Phage typing of $S$. aureus isolates}

The $S$. aureus isolates obtained in this study were phage typed by Dr Rosdahl at the Statens Seruminstitut, Copenhagen, Denmark. All were typed with European phages at routine test dilution (RTD). When not typable at RTD, the isolates were typed at $100 \times$ RTD and those that were still not typable were subjected to further typing at $1000 \times$ RTD.

\section{Antibiotic sensitivity testing}

Antibiotic sensitivity of the isolates was determined by the method of Ericsson and Sherris ${ }^{14}$ on MuellerHinton Agar (Oxoid). The plates were incubated at $35^{\circ} \mathrm{C}$ for $24 \mathrm{~h}$ except when testing for methicillin resistance, for which the plates were incubated at $29^{\circ} \mathrm{C}$ for several days. The antibiotic disks used (AB Biodisk, Pyramidvagen, Solon, Sweden) contained penicillin $\mathrm{G} 1.5$ units, streptomycin $10 \mu \mathrm{g}$, tetracycline
$10 \mu \mathrm{g}$, gentamicin $10 \mu \mathrm{g}$, erythromycin $10 \mu \mathrm{g}$, methicillin $5 \mu \mathrm{g}$, kanamycin $10 \mu \mathrm{g}$, chloramphenicol $10 \mu \mathrm{g}$ and fusidic acid $5 \mu \mathrm{g}$. $S$. aureus ATCC 25923 was used as control.

\section{Results}

\section{Isolation}

A total of 166 S. aureus isolates was obtained in the course of this study. Of these, 37 were from the anterior nares of 65 apparently healthy hospital personnel, giving a nasal carrier rate of $57 \%$. Ten were from infected wounds and eight from patients with conjunctivitis. Most isolates (111) were obtained from cases of skin sepsis. All were coagulase- and mannitolpositive gram-positive cocci.

\section{Production of extracellular enzymes}

Protease. With $124(75 \%)$ of the isolates, protease production was demonstrated by the presence of a clear zone around the line of streak after addition of acid mercuric chloride; $95 \%$ of the isolates from skin, $78 \%$ from eyes and wounds, but only $11 \%$ from the anterior nares produced protease (table I).

DNAase and RNAase production. DNAase was produced by $156(94 \%)$ of the isolates-98\% of skin isolates, $84 \%$ of nasal and $89 \%$ of conjunctival and wound isolates (table I). In contrast, RNAase activity was detected in only $87(52 \%)$ of the isolates $-76(68 \%)$ skin isolates, $4(11 \%)$ nasal isolates and $5(39 \%)$ of isolates from eye and wound samples.

\section{Phage typing}

Of the 166 isolates typed, 18 (11\%) were lysed by group I phages, 41 (25\%) by group II phages, $25(15 \%)$ by group III phages and $17(10 \%)$ by phages from mixed groups (table II). On the basis of their lytic pattern, $5(3 \%)$ of the isolates were assigned to the $83 \mathrm{~A}$ complex group and $6(4 \%)$ belonged to the 94/96 complex. Only one $(0.6 \%)$ isolate was of phage type 95. The largest single group, containing $53(32 \%)$ isolates, was not lysed by any of the phages used; these isolates were regarded as untypable (table II).

Table I. Detection of protease, DNAase and RNAase activity in $S$. aureus isolates on solid media containing gelatin, DNA or RNA

\begin{tabular}{lc|rrr}
\hline \multicolumn{1}{c}{ Source of isolate } & $\begin{array}{c}\text { Number of } \\
\text { isolates tested }\end{array}$ & \multicolumn{3}{c}{ Number (\%) producing } \\
\cline { 3 - 5 } & 111 & protease & DNAase & RNAase \\
\hline Skin sepsis & 37 & $106(95)$ & $109(98)$ & $76(68)$ \\
Nasal swabs & 18 & $14(78)$ & $31(84)$ & $4(11)$ \\
Eye and wound infections & 166 & $16(89)$ & $7(39)$ \\
Total & & & $156(94)$ & $87(52)$ \\
\hline
\end{tabular}


Table II. Phage-typing of S. aureus isolates from clinical sources at OAUTHC, lle-lfe, Jan. 1988-Sept. 1989

\begin{tabular}{|c|c|c|c|c|c|c|c|c|c|c|}
\hline \multirow{2}{*}{ Source of isolate } & \multirow{2}{*}{$\begin{array}{c}\text { Number of } \\
\text { isolates }\end{array}$} & \multirow{2}{*}{$\begin{array}{l}\text { Percent } \\
\text { of total }\end{array}$} & \multicolumn{8}{|c|}{ Number of isolates (percent from source) sensitive to phages of } \\
\hline & & & $\underset{\text { I }}{\text { group }}$ & $\begin{array}{c}\text { group } \\
\text { II }\end{array}$ & $\begin{array}{c}\text { group } \\
\text { III }\end{array}$ & $\begin{array}{c}\text { 83A } \\
\text { complex }\end{array}$ & $\begin{array}{c}94 / 96 \\
\text { complex }\end{array}$ & $\begin{array}{l}\text { type } \\
95\end{array}$ & NI & $\begin{array}{c}\text { non- } \\
\text { typable }\end{array}$ \\
\hline Skin sepsis & 111 & 67 & $7(6)$ & $31(28)$ & $10(9)$ & $3(3)$ & $3(3)$ & 0 & $17(15)$ & $40(36)$ \\
\hline Nasal swabs & 37 & 22 & 4(11) & $3(8)$ & $14(38)$ & $2(5)$ & $3(8)$ & $1(3)$ & 0 & $10(27)$ \\
\hline Eye and wound infections & 18 & 11 & $7(39)$ & $7(39)$ & $1(6)$ & 0 & 0 & 0 & 0 & $3(17)$ \\
\hline Total & 166 & 100 & $18(11)$ & $41(25)$ & $25(15)$ & $5(3)$ & $6(4)$ & $1(0 \cdot 6)$ & $17(10)$ & $53(32)$ \\
\hline
\end{tabular}

$\mathrm{NI}=$ mixed group, i.e., $S$. aureus isolates lysed by phages of several groups.

Only $11 \%$ of nasal isolates of $S$. aureus from healthy subjects produced protease, but all belonged to phage group III. In contrast, $95 \%$ and $75 \%$ of isolates from skin sepsis and eye and wound infections, respectively, were proteolytic and these were evenly distributed among all phage groups. This indicates that ability to produce protease may be inherent amongst pathogenic staphylococci but much less manifest in $S$. aureus isolates from healthy carriers.

\section{Antibiotic sensitivity testing}

The 166 isolates were tested for susceptibility to nine antibiotics. Almost all $(99 \%)$ isolates were resistant to penicillin. Resistance to tetracycline was also widespread $-78 \%$ of isolates tested were resistant; $25 \%$ of isolates were resistant to streptomycin and $19 \%$ resistant to chloramphenicol. The incidence of resistance to methicillin was $7 \%$ and only $3 \%$ of isolates were resistant to erythromycin. Resistance to gentamicin $(2 \%)$ and fusidic acid $(1 \%)$ was rare and none of the isolates was resistant to kanamycin.

\section{Discussion}

Different $S$. aureus isolates have many varied characteristics, some of which are associated with their virulence and pathogenicity. A knowledge of the characteristics of $S$. aureus strains within a given environment may be used as a means of identifying strains that are more likely to lead to outbreaks of staphylococcal infection in that environment.

Various strains of $S$. aureus produce extracellular enzymes. The role of these enzymes in the pathogenesis of infection has been discussed ${ }^{15,16,17}$ and it is suggested that there is a direct relationship between the virulence characteristics of $S$. aureus strains and their ability to produce extracellular enzymes. A large proportion of the isolates tested in this study produced DNAase. However, only a minority of the nasal isolates from apparently healthy individuals produced protease and RNAase whereas $75 \%$ of the isolates from clinical sources produced protease and 52\% produced RNAase. Therefore, it seems that these results are in line with earlier reports that demonstrated a correlation between virulence and production of extracellular enzymes.

From our results, it can be seen that a large proportion $(32 \%)$ of the isolates were untypable under the conditions of the phage-typing test. This result is not entirely unexpected because the phages used were "European" rather than local and this highlights the importance of isolating and testing phages which may be used in typing local strains of $S$. aureus. However, $68 \%$ of the isolates were typable and several different groups were identified. The biggest group, group II, contained $25 \%$ of the isolates. This is similar to the results obtained by V.T. Rosdahl (personal communication) with isolates from Danish sources, $18.8 \%$ of which belonged to phage group II. The percentages of organisms in several other groups were also similar when comparisons were made between isolates from Nigeria and Denmark (V.T. Rosdahl, personal communication); $11 \%$ of Nigerian isolates and $12.3 \%$ of Danish isolates were in group I, and the figures for group III were $15 \%$ and $11.7 \%$ for Nigeria and Denmark, respectively. Furthermore, $10 \%$ of Nigerian isolates and $7 \cdot 1 \%$ of the Danish isolates belonged to the mixed group. The only striking differences were that only $4 \%$ of Nigerian isolates were in the $94 / 96$ complex whereas $13.3 \%$ of the Danish isolates belonged to this group, and only one Nigerian isolate but $18.1 \%$ of the Danish isolates were of type 95 . These results indicate that there are some noticeable differences in the distribution patterns of phage-types in both localities but that the similarities may be more important that the differences. The differences may also be affected by sample size which was very large (more than 18000 isolates) in the Danish study. Our results also indicate that resistance to penicillin, tetracycline and streptomycin is fairly evenly distributed amongst isolates from different sources (table III) whereas methicillin, erythromycin and gentamicin resistances are associated with phage group I and 83A (also 94/96 and NT) and are more likely to be found in nasal isolates than in isolates from skin lesions.

The antibiotic sensitivity patterns of $S$. aureus strains isolated in Nigeria has been the subject of several studies. ${ }^{10,18-20}$ In each of these studies, the incidence of resistance to several antibiotics was found 
Table III. Antibiotic resistance of $S$. aureus isolates from infected hospital patients and from staff nasal carriers at OAUTHC, lle-lfe, Jan. 1988-Sept. 1989

\begin{tabular}{l|cccc}
\hline & \multicolumn{3}{|c}{ Number (\%) of resistant isolates from } \\
\cline { 2 - 4 } & $\begin{array}{l}\text { skin sepsis } \\
(\mathrm{n}=111)\end{array}$ & $\begin{array}{c}\text { nasal swabs } \\
(\mathrm{n}=37)\end{array}$ & $\begin{array}{c}\text { wound and eye infections } \\
(\mathrm{n}=18)\end{array}$ & $\begin{array}{c}\text { Total (\%) } \\
(\mathrm{n}=166)\end{array}$ \\
\hline Penicillin & $110(99)$ & $37(100)$ & $17(94)$ & $164(99)$ \\
Tetracycline & $84(76)$ & $31(84)$ & $15(82)$ & $130(78)$ \\
Streptomycin & $24(22)$ & $12(32)$ & $5(29)$ & $41(25)$ \\
Chloramphenicol & $19(17)$ & $8(22)$ & $4(24)$ & $31(19)$ \\
Methicillin & $2(2)$ & $8(22)$ & $5(25)$ & $15(9)$ \\
Erythromycin & $1(1)$ & $4(11)$ & 0 & $5(3)$ \\
Gentamicin & 0 & $4(11)$ & 0 & $4(2)$ \\
Fusidic acid & $1(1)$ & 0 & 0 & $1(1)$ \\
& & & & \\
\hline
\end{tabular}

to be very high. Rosdahl and Rosendal ${ }^{21}$ have reported the prevalence of the 95-complex phage-types among Danish patients. These strains were reported to be high-level penicillinase producers and resistant to metal ions. The 83A-complex phage-types have also been reported in Denmark. ${ }^{22}$ In this study, the incidence of resistance encountered was generally lower than that observed in earlier studies but was higher than the incidence of similar resistance in Denmark (V.T. Rosdahl, personal communication). The reasons for the observed reduction in the incidence of resistance to antibiotics in Nigeria are not apparent but the fact that the incidence is still significantly higher in Nigeria than in Denmark indicates that there is still great need to control the availability and use of antibiotics in Nigeria.

We are very grateful to $\mathrm{Dr}$ V. T. Rosdahl of the Statens Seruministitut, Copenhagen, Denmark for collaborating with us in performing the phage-typing, some in-vitro antibiotic sensitivity testing and for technical information used in this study. We thank Dr O. Taiwo, Ms Anne Ebri and Mr Kolawole for their assistance.

\section{References}

1. Shinefield HR. Staphylococcal infections. In: Remington JS, Klein JO (eds) Infectious disease of the fetus and newborn infant. Philadelphia, Saunders, WB \& Co. 1976:979-1019.

2. Musher DM, McKenzie SO. Infections due to Staphylococcus aureus. Medicine (Baltimore) 1977; 56: 383.

3. White A, Brooks GF. Furunculosis, pyoderma and impetigo. In: Hoeprich PD (ed) Infectious diseases, 2nd edn. Hangerstown, Harper and Row. 1977: 785-793.

4. Dillon HC, Ware JC. Sources and susceptibilities of staphylococci isolated from children. Am J Dis Child 1981; 135 : 427-430.

5. Speers R, Shooter RA, Hewitt JH. Contamination of nurses' uniforms with Staphylococcus aureus. Lancet 1969; 2 : 233235.

6. Wolinsky E, Lipsitz PJ, Mortimer EA, Rammelkamp CH. Acquisition of staphylococci by newborns: direct versus indirect transmission. Lancet 1960; 2 : 620-622.
7. Hawiger J, Koenig MG. Staphylococcal diseases. In: Sanford JP, Luby JP (eds) Infectious diseases. New York, Grune and Stratton. 1981: 177-184.

8. Parker MT. The significance of phage-typing patterns in Staphylococcus aureus. In: Easmon CSF, Adlam C (eds) Staphylococci and staphylococcal infections. London, Academic Press. 1983: 33-62.

9. Odugbemi TO, Ajasin MA, Ogunbi O. Staphylococcal scalded skin syndrome in Nigerian children: a report of three cases. J Trop Med Hyg 1976; 79: 260-263.

10. Rotimi O, Odugbemi TO, Fadahunsi O, Ogunbi O. Penicillin resistance in Staphylococcus aureus: prevalence of penicillinase producing strains in Lagos University Teaching Hospital. Nig Med J 1979; 9: 307-310.

11. Hankin L, Anagnostakis SL. The use of solid media for detection of enzyme production by fungi. Mycologia 1975; 67: 597-607.

12. Jeffries CD, Holtman F, Guse DG. Rapid method for determining the activity of micro-organisms on nucleic acids. J Bacteriol 1957; 73: 590-591.

13. Bauer AW, Kirby WWM, Sherris JC, Turck M. Antibiotic susceptibility testing by a standardized single disk method. Am J Clin Pathol 1966; 45: 493-496.

14. Ericsson HM, Sherris JC. The agar dilution method. Acta Pathol Microbiol Scand Sect B 1971; Suppl 217: 11-12.

15. Abramson C. Staphylococcal enzymes. In: Cohen JO (ed) The staphylococci. New York, Wiley Interscience. 1972: 187248.

16. MacFaddin JF. Biochemical tests for identification of medical bacteria, 2nd edn. Baltimore, Williams and Wilkins. 1980 64-76.

17. Willett HP. Staphylococcus. In: Joklik WK, Willett HP, Amo DB (eds) Zinsser microbiology, 17th edn. USA, AppletonCentury-Crofts. 1980: 532-552.

18. Paul MO, Lamikanra A, Aderibigbe DA. Nasal carriage of coagulase-positive staphylococci in a Nigerian hospital community. Trans Roy Soc Trop Med Hyg 1982; 76: 319323.

19. Lamikanra A, Paul BD, Akinwole OB, Paul MO. Nasal carriage of Staphylococcus aureus in a population of healthy Nigerian students. J Med Microbiol 1985; 19: 211-216.

20. Lamikanra A, Olusanya OI. A long-term study of nasal carriage of Staphylococcus aureus in healthy Nigerian students. Trans Roy Soc Trop Med Hyg 1988; 82: 500-502.

21. Rosdahl VT, Rosendal K. Correlation of penicillinase production with phage type and susceptibility to antibiotics and heavy metals in Staphylococcus aureus. J Med Microbiol $1983 ; 16$ : $391-399$.

22. Rosendal K, Jessen O, Faber V, Bentzon MW. Frequency, phage types and antibiotic resistance of Staphylococcus aureus isolated from blood cultures in Denmark-19751981. Scand J Infect Dis 1983; Suppl 41 : 19-26. 